\title{
Study on Scenario Construction of Major Emergency for Critical Infrastructure
}

\author{
Jingjing Wang ${ }^{1, a^{*}}$, Wei Zhu ${ }^{1, b}$ and Yukun $\mathrm{Gao}^{2, \mathrm{c}}$ \\ ${ }^{1}$ Beijing Research Center of Urban System Engineering, China \\ ${ }^{2}$ University of Science \& Technology Beijing, China \\ awangjingjing183@126.com, 'zhuweianquan@126.com c gaoyukunustb@126.com
}

\begin{abstract}
Keywords: critical infrastructure; major emergency; scenario construction; emergency capability; correlation

Abstract. Critical infrastructure is the basis for normal operation and healthy development of the city. With the correlation and dependence between critical infrastructure increasingly strengthened, critical infrastructure disasters often bring huge economic losses and serious social impact, and improving emergency response capacity of critical infrastructure has become an important prerequisite for protecting normal operation of the city. Combined with theoretical methods of scenario construction, this paper regards critical infrastructure as the object of research, and studies the method of scenario construction of critical infrastructure and emergency capacity evaluation from scenario analysis, emergency task analysis and emergency capacity evaluation, then apply the common method to gas multi-gate station incident scene, which verifies the feasibility of this method.
\end{abstract}

\section{Introduction}

Today's society is increasingly depended on the services provided by the infrastructure system to maintain its normal operation, but in recent years, with growing association between critical infrastructures, whether the fluctuation of local state and the aging failure of component within the system, or the malicious attack and natural disaster from external system, are likely to cause unpredictable chain reaction. Take the North America blackout in 2003 for example, the incident greatly affected the transportation, commerce, national security, health care, communication, finance, heating, electronic products, and even entertainment and leisure industry. Up to 29 hours blackout caused direct economic losses of $\$ 30$ billion and significant social impact[1]. So, it's imperative to study the evolution of major emergencies of critical infrastructure and propose emergency task, and the theory and methodology of scenario construction present an effective solution to carry out emergency preparedness work.

\section{Characteristics of Critical Infrastructure Major Emergency}

In today's society, our dependency on the critical infrastructure becomes more and more high. In order to meet the needs of industries, the structure of infrastructure systems become more complex, and the correlation and interdependency of critical infrastructure is growing[2]. The correlation of critical infrastructure including physical correlation, geographic correlation, and information correlation. Physical correlation refers to that a class of critical infrastructure offers products or services for another important infrastructure, such as rail network delivery coal and other fuels which are used by electricity grid. Geographic correlation refers to the different critical infrastructure located in the same geographical area, such as it is often the case that gas pipeline usually damaged when repairing heat pipes, causing a gas leak explosion. Information correlation involves the running of critical infrastructure rely on the information which another important infrastructure transfer, such as electricity facilities require control information which communication network transfer.

The complexity and correlation of critical infrastructure make the system more powerful, but also more vulnerable and at greater risk. While because critical infrastructure are closely related to 
people's lives, it will inevitably affect people's life and production in case of accidents. Major emergencies which can't be repaired in short time is likely to trigger people's resistance, and lead to mass events and spreading of rumor, resulting in extremely bad social impact.

Major emergency of critical infrastructure can be classified into two main categories, one is physical damage within the system of critical infrastructure, which only have an impact on its own device operation, the other, if the critical infrastructure is disturbed in the running, such as function damage caused by natural disasters, because of the coupling effect between the infrastructures, single accident of infrastructure system often exceeds the boundary and spreads to other associated infrastructure systems, with spreading in the wider scope and causing more damage, and even cause service interruptions, which directly affect normal operation of the city[3,4]. Once a significant impact on people's life and production, it will inevitably cause serious social impact.

However, whether the fluctuation of local state and the aging failure of component within the system, or the malicious attack and natural disaster from external system, are likely to cause unpredictable chain reaction, resulting in a large area of damage and failure of infrastructures across the region, thereby endangering public safety or national security[5-7]. For example, traffic lights are very likely not to work properly after a power outage, which will affect the running of regional transportation system, resulting in traffic jams or accidents, in addition to a power outage, it may also lead to gas compressor station stopping work, which will affect the fuel supply of gas power plant, and may further adversely affect the supply of electricity.

\section{Scenario Construction of Critical Infrastructure Incidents}

Scenario construction of critical infrastructure is a risk management tool to prepare for future disaster, according to the bottom-line thinking[8]. Based on risk assessment and vulnerability analysis, this method makes scientific assumption of major incidents that may occur during a certain period, and analyzes the changing process of scenarios, consequences of the disaster, and the task lists which the scene should to deal with. Comparing with emergency capacity of the current situation, it finally proposes main points at all levels, prevention and emergency preparedness measures[9]. Scenario construction of critical infrastructure includes scenario description, consequence analysis, emergency task and ability analysis, as shown in Table 1.

Table 1. Scenario construction of major emergency for critical infrastructure

\begin{tabular}{|c|c|c|}
\hline \multirow{2}{*}{$\begin{array}{c}\text { scenario } \\
\text { construction }\end{array}$} & \multicolumn{2}{|c|}{ the detailed process } \\
\hline $\begin{array}{c}\text { scenario } \\
\text { simmulation }\end{array}$ & $\begin{array}{c}\text { correlation simmulate of critical } \\
\text { infrastructure }\end{array}$ & $\begin{array}{c}\text { consequence analysis of service and } \\
\text { society layer }\end{array}$ \\
\hline $\begin{array}{c}\text { consequence } \\
\text { analysis }\end{array}$ & physical simulation & sociological analysis \\
\cline { 2 - 3 } $\begin{array}{c}\text { emergency task } \\
\text { and ability }\end{array}$ & complex network simulation & questionnaire \\
\hline
\end{tabular}

Scenario Description. Using a particular method, scenario description makes a scientific description of the likelihood that emergency will occur, the way and process of development, and the serious consequences Scenario description of critical infrastructure carries out from the facility layer, service layer and society layer. Facility layer considers the impact of infrastructure accident on other critical infrastructures. Service layer focuses on the impact on services such as mall and tourism after a series failure of critical infrastructure. Social layer is concerned about public opinion influence, disease, and security problems caused by emergency.

Consequence Analysis. Through scenario description of the consequences of major emergency, this part uses scientific methods to analyze the consequences, including physical simulation, complex network simulation, sociological analysis and questionnaires. Physical simulation mainly used to simulate the influencing scope and degree of emergencies on a certain critical infrastructure. Complex network simulation focuses on the associated impacts between critical infrastructures. Sociological analysis and questionnaires is mainly used to analyze the degree of influence on service layer and society layer. 
Emergency Task and Ability Analysis. For major emergency scenario of important infrastructure, this part studies the emergency tasks of each department based on business continuity management theory, including preparatory works to reduce the risk before accident, the response behaviors to reduce the loss once the accident happen, and measures to return to normal after accident. Business continuity management needs to consider lots of resources, including personnel, information data, built environment and supporting facilities, equipment materials, communications systems, transportation, finance, partners, suppliers and downstream users[10]. Emergency common task list of critical infrastructure is shown in Table 2.

Table 2. Emergency common task list

\begin{tabular}{|c|c|c|}
\hline \multirow{4}{*}{ Phase Division } & \multicolumn{2}{|c|}{ Emergency Task } \\
\hline \multirow{3}{*}{ preparation } & hazard identification & public education \\
\cline { 2 - 3 } & alternative energy source store & daily maintenance and construction \\
\cline { 2 - 3 } & running state monitor & emergency state agreement \\
\cline { 2 - 3 } & professional training & emergency plan compile \\
\hline \multirow{3}{*}{ response } & key users protect & information communicate \\
\cline { 2 - 3 } & facility maintenance & protect people's livelihood \\
\cline { 2 - 3 } & social control & weather safeguard \\
\hline recover & \multicolumn{2}{|c}{ service restoral } \\
\hline
\end{tabular}

\section{Scenario Construction of Multi-Station Gas Supply Stop Event}

Set the scene as: one winter's night, long-distance pipeline interrupts because of a accident, and three gas stations of a large northern city disrupts. After the accident the city's gas supply capacity is down by 37 percent.

Scenario Simulation and Consequence Analysis. According to the correlation analysis results of urban public facilities, gas as an important energy power of heating and electricity, gas supply shortage will lead to capacity of heating and electricity decrease, secondly, gas, heating and electricity, as important public facilities, are energy sources for city running. The accident will lead gas, heating and electricity can't meet the operational need of the city, causing reduction in the social service level, which directly influence business, health, transportation, tourism and other systems. Finally, the corresponding service provided by the city will fail to meet the residents' demand, which will result in a variety of events at social level. The influence on the operational level is represented by Fig.1.

At the facility level, due to the emergence of multi-stations occurs in winter, the stations have no adjustment space. According to the simulation of state changes by the gas network simulation system, it is necessary to implement the program of pressing gas quantity to guarantee its supply. In order to prevent further deterioration of the pipe network condition and protect cooking gas of urban residents, thermal power plants on the high-pressure pipe network need an emergency stop and city gas load need to drop, however, it will lead to great impact on city heating. Based on the thermodynamic system physical simulation of heat pipe thermal system simulation system, it is necessary to start fuel boiler and restart thermal power plants. In order to ensure stability of the entire pipe network balance, it requires to shut down half of regional boilers connected to gas network, so $70 \%$ of the heating area will be affected, and most public buildings heating can not be guaranteed, the temperature of part rooms will under 9 degrees. Residents will use through air condition, electric heater and other electrical equipments for heating, which results in substantial growth in electric load grids at morning rush-hour. Electricity company will restrict electricity after load-dispatching operation, related to the various types of users except special and first level users. 

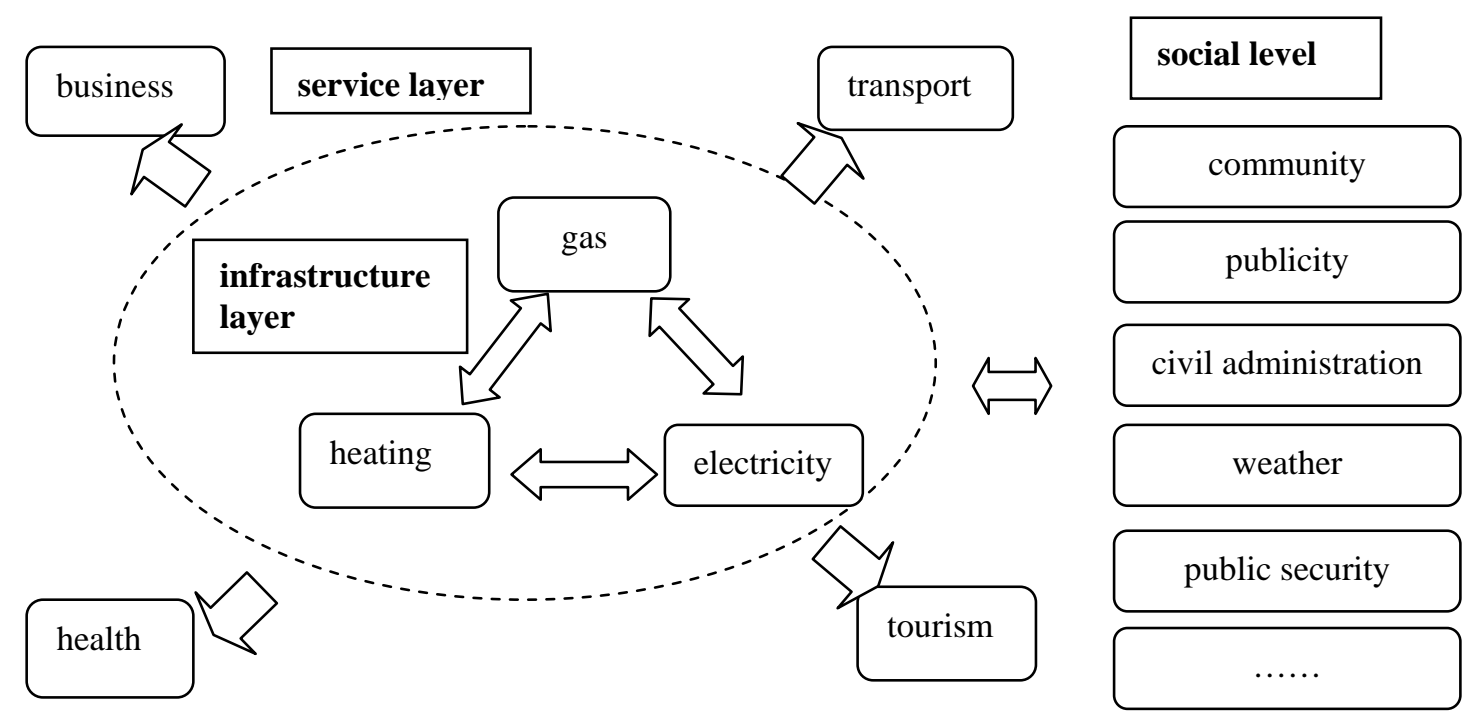

Fig.1 Scenario construction of major emergency for critical infrastructure

At the service level, the incident affect greatly on public transportation, commerce, tourism and health care systems. As the outbound pressure of gas regulator station B lower than the allowable aerated pressure of gas bus, the regulating station connecting to the CNG filling stations will not be aerated. In view of the gas and electricity gap are very large, the policies of closing the mall except the supermarkets which provide the necessities will be implemented. Because the heating can not be guaranteed, key populations feel uncomfortable because of the low room temperature, and residents will purchase electric heating equipment. Based on this phenomenon, business and health departments should allocate warm materials and medicines to protect the supply. Influenced by city reduced gas load, the office area and factories can not operate properly, so some companies take measures to adjust work mode, such as allowing employees work flexible at home, and making migrant workers return home in advance, which creates a spring phenomenon at station, so the railway sector should adjust the rail capacity to prevent a large number of passengers stranded in the station.

At the social level, because of the gas incident, heating and electricity have also been severely affected, some regions appears a low temperature heating and power cuts situation ,which has seriously affected the lives of the residents, causing strong dissatisfaction of residents. However, some criminals provoke some residents to government, which lead to mass incidents, so the public security departments should quickly organized forces to the scene of the accident, and response in time to prevent the situation from getting worse. Because some residents visit family and friends, it is very important to detect and resolve community problems of instability. The community policeman will strengthen the control of home visits and community patrolling to discover and resolve various uncertainties with the territorial government. Civil affairs departments are responsible for the allocation and delivery of warm materials and daily necessities under the emergency committee's instructions.

Emergency Task Analysis. Through the study of multi-station gas supply stop incident, we specify the common tasks list of Table 1, according to the prevention phase, the response phase and the recover phase we present 49 emergency tasks of 17 categories.

Recommendations to Enhance Emergency Response Capabilities. According to the task and capability analysis of multi-station gas supply stop event, we present recommendations to enhance emergency response capabilities, based on business continuity, social mobilization and risk communication.

Recommendations on business continuity include strengthening gas transmission support capabilities of gas system 、 network optimization、alternate air source reserve v pressing gas quantity plan、 alternate heat source of heating system、strengthening emergency redeployment important user security and medicines, warm material reserves. Recommendations on risk communication include strengthening regional interaction、construction of combined heat power 
gas control and generation system、 public opinion guidance、 crisis communication mechanisms、 important people care and prevention、 public education and carry out comprehensive drills. The main recommendations on social mobilization include increasing advocacy public to conserve electricity and gas, the development of community plans and family plans.

\section{Conclusion}

This article analyzed the features of major emergencies of critical infrastructure, and raised common method on scenario construction of major emergency for critical infrastructure. Through the analysis of the internal and across critical infrastructure, and social operation services, we studied the evolution process of scenario, then refined emergency tasks of major emergencies matching with the existing emergency response capacity, and ultimately proposed deficiencies. Finally, the sample application demonstrated the feasibility of the method, and presented specific recommendations to enhance emergency capabilities, which applies to the emergency risk response work of other infrastructures as well.

\section{Acknowledgement}

This research was supported by the Beijing Postdoctoral Research Foundation, all support is gratefully acknowledged.

\section{References}

[1] L. Tiemin, Studies on scenes construction of emergency planning-part I of emergency planning technology based on "scene-task-ability", Journal of Safety Science and Technology. 8 (2012) 5-12.

[2] US/DHS. “National Planning Scenarios,” 2006.

[3] W. Zhili and L. Xiao, Research on emergency strategy of civic critical infrastructures under urgent events , China Safety Science Journal, 21(2011) 168-175.

[4] W. Xuping and Y. Xiangying, A methodology of scenario construction and deduction of unconventional emergency, Journal of UESTC, 15(2013) 22-27.

[5] K. G. Crowther and Y. Y. Haimes, Development of the multiregional inoperablity input-output model for spatial explicitness in preparedness of interdependent regions, Systems Engineering, 13 (2013) 28-46.

[6] M. Zijun, F. Qi, L. Yuanwen, Interdependent response of urban infrastructure's networks, Journal of huazhong university of science and technology, 37(2009) 64-67.

[7] B Gulay, O Linet, C Ahmet, An interactive approach for hierarchical analysis of helicoptor logistics in disaster relief operations, European journal of operational research, 1 (2002) 118-133.

[8] S Roberto, Analysis of Interdependencies between Italy's Economic Sectors, Critical Infrastructure Protection. Boston: Springer, 2008.

[9] G Orhan, A Alan. Modeling infrastructure interdependencies using petri nets, IEEE 2003.

[10]W. Shuliang and C. Xueguang, Vulnerability study of interdependent infrastructure systems under cascading failures, Computer Simulation. 8 (2014) 310-316. 